\title{
Trocas gasosas, características das folhas e crescimento de plantas jovens de Cupania vernalis Camb. submetidas a diferentes níveis de sombreamento
}

\author{
Gas exchange and initial growth of young leaves of Cupania vernalis camb. \\ submitted to different shading levels
}

\author{
Érico de Castro Lima Junior ${ }^{1}$ Amauri Alves de Alvarenga ${ }^{2}$ Evaristo Mauro de Castro ${ }^{3}$ \\ Carlos Vinício Vieira ${ }^{1}$ Hilton Morbeck de Oliveira ${ }^{4}$
}

\section{RESUMO}

Cupania vernalis Camb. é uma espécie arbórea pertencente à família sapindaceae, conhecida popularmente como camboatá, camboatã. É uma espécie de grande importância pelo seu uso em plantios mistos destinados à recuperação de áreas degradadas e preservação permanente. Este estudo teve como objetivo básico caracterizar o desempenho ecofisiológico desta espécie sob condições de viveiro. Avaliou-se o efeito de quatro níveis de irradiância (Pleno sol, 30\%, 50\% e $70 \%$ de sombreamento) sobre as trocas gasosas, concentração de nitrogênio, clorofilas foliares e crescimento de plantas jovens de Cupania vernalis. As plantas submetidas a $50 \%$ de sombreamento acumularam maior massa seca de folha, caule e massa seca total em comparação com as cultivadas a pleno sol, não sendo observada diferença quanto à massa seca de raízes. A maior taxa fotossintética e condutância estomática foram observadas em folhas de plantas crescidas sob pleno sol e $30 \%$ de sombreamento. Plantas sob condições mais sombreadas apresentaram teores mais elevados tanto de clorofilas quanto de nitrogênio nas folhas. Fato semelhante ocorreu com outras características como altura, diâmetro de caule e área foliar. Essas últimas características constituem fatores determinantes da qualidade de mudas. Os resultados possibilitaram concluir que as mudas desta espécie devem ser formadas sob condições de viveiro com sombreamento de 50\% ou $70 \%$ para que se obtenham mudas de melhor qualidade.

Palavras-chave: camboatá, massa seca, clorofilas, radiação, fotossíntese.

\section{ABSTRACT}

Cupania vernalis Camb. is an arboreal species belonging to the sapindaceae family, known popularly as

\begin{abstract}
"Camboatá", "Camboatã". This species has great economical importance by its use in mixed plantings trying to recovery permanent degraded and preservation areas. This study aimed, basically, at characterizing the ecophysiological aspects of this species under nursery conditions. The effect of four levels of irradiance (Full sunshine, 30\%, 50\% and $70 \%$ of shading) on the gas exchange, concentration of nitrogen; leaf chlorophylls and initial growth of young plants of Cupania vernalis was evaluated. The results showed that the plants submitted to $50 \%$ of shading have accumulated more leaf, stem dry matter and total as compared to that cultivated under full sunshine. No difference was found in relation to root dry matter. Higher photosynthetic rate and stomatal conductance on leaves were observed in the plants grown under full sunshine and $30 \%$ of shading. Plants under more shaded conditions presented higher contents of chlorophyll and nitrogen in leaves, a similar fact took place with the other characteristics such as height, stem diameter and leaf area. These latter characteristics determine seedling quality. It was concluded that the seedlings of that species should be grown in the nursery under conditions of 50 or $70 \%$ shading in order to improve seedling quality.
\end{abstract}

Key words: camboatá, dry mass, chlorophyll, radiation, photosynthesis.

\section{INTRODUÇÃO}

Cupania vernalis Camb., conhecida popularmente com o nome de camboatã ou camboatá, é uma espécie nativa que ocorre tanto no interior de matas primárias como em todos os estádios de

${ }^{1}$ Programa de Pós-graduação em Agronomia/Fisiologia Vegetal na Universidade Federal de Lavras (UFLA), Rua Alvira de Souza Maximo, 65, Lavras, MG, Brasil. E-mail: limajunior@ufla.br.

${ }^{2}$ Departamento de Biologia (DBI), Setor Fisiologia Vegetal, (UFLA), Lavras, MG, Brasil.

${ }^{3}$ DBI, UFLA, Lavras, MG, Brasil.

${ }^{4}$ Universidade Federal do Mato Grosso, Cuiabá, MT, Brasil. 
formações secundárias. No contexto ecológico, a espécie é classificada como secundária adaptada à insolação direta. As plantas produzem frutos comumente consumidos por algumas espécies de pássaros sendo consideradas de grande potencial para uso em plantios mistos destinados à recomposição de áreas degradadas e de preservação permanente (LORENZI, 2000).

As formações florestais do Brasil, em geral, vêm sofrendo níveis significativos de degradação, quer seja devido ao avanço da fronteira agropecuária como a construção de usinas hidrelétricas. Para atenuar esses problemas ambientais, torna-se necessário o desenvolvimento de estudos e programas para a regeneração desses ambientes degradados (NASCIMENTO \& SADDI, 1992; ALMEIDA et al., 2004). Alguns estudos têm sido dirigidos para recuperar tais ambientes, enfocando diferentes aspectos do desenvolvimento vegetal, como a fisiologia da germinação de sementes e o desenvolvimento inicial de várias espécies de interesse florestal. Entretanto, são ainda incipientes os estudos sobre a propagação e crescimento inicial de espécies nativas (ALMEIDA et al. 1994; WHITMORE, 1996; SCALON et al., 2001).

Dentre os fatores físicos do ambiente, a luz desempenha, indubitavelmente, um papel relevante na regulação da produção primária, contribuindo de forma efetiva para o crescimento das plantas. Geralmente, as características inerentes ao crescimento são utilizadas para inferir o grau de adaptabilidade à baixa disponibilidade de luz. O sucesso na adaptação de uma espécie em diferentes condições de radiação está relacionado com a eficácia e rapidez com que os padrões de alocação de biomassa e comportamento fisiológico são ajustados. A maior ou menor plasticidade adaptativa das espécies às diferentes condições de radiação solar depende do ajuste de seu aparelho fotossintético, de modo a garantir maior eficiência na conversão da energia radiante em carboidratos e, conseqüentemente, maior crescimento (NAVES et al., 1994; DIAS-FILHO, 1997; ALVARENGA et al., 1998; VILELA \& RAVETTA, 2000; CAMPOS \& UCHIDA, 2002).

A adaptação das plantas a uma determinada condição de irradiância está ainda associada à quantidade de clorofilas e nitrogênio foliar, já que a luz é considerada como um dos principais fatores associados ao metabolismo clorofiliano. As clorofilas encontram-se em constantes processos de síntese e degradação (fotooxidação), sob radiações intensas, o processo degradativo ocorre de forma pronunciada, enquanto sob condições de sombreamento, as concentrações foliares de clorofilas tendem a aumentar (KRAMER \& KOZLOWSKI, 1979; WHATLEY \& WHATLEY, 1982; BRAND, 1997;ALVARENGAet al., 1998).

Em muitas espécies, altas taxas de trocas gasosas estão associadas a altas concentrações de nitrogênio foliar. Entretanto, poucos estudos relacionam a concentração de nitrogênio foliar com trocas gasosas sob diferentes níveis de irradiância (ELLSWORTH \& REICH, 1992; ALMEIDA, 2001).

O objetivo deste trabalho foi avaliar o efeito de diferentes níveis de sombreamento sobre o crescimento inicial, trocas gasosas, concentração de nitrogênio e clorofilas foliares em plantas jovens de Cupania vernalis, sob condições de viveiro.

\section{MATERIAL E MÉTODOS}

O trabalho foi conduzido no período de março a novembro de 2003, sob condições de viveiro, no Setor de Fisiologia Vegetal, Departamento de Biologia, Universidade Federal de Lavras (UFLA) situada em Lavras, MG. O município está localizado na região sul do estado de Minas Gerais, a $918 \mathrm{~m}$ de altitude, $21^{\circ} 14^{\prime}$ latitude sul e longitude $45^{\circ} 00^{\prime} \mathrm{W}$ GRW.

As mudas foram oriundas de sementes coletadas em plantas matrizes localizadas no município de Bom Sucesso, MG, às margens do Rio Grande, onde atualmente se localiza o reservatório da Usina Hidrelétrica do Funil. Essas mudas foram cultivadas em bandejas de isopor contendo como substrato, terra de subsolo, areia e esterco bovino, na proporção de 7:2:1 e adubado com $2 \mathrm{~kg}$ de fertilizante $4: 14: 8 \mathrm{~m}^{-3}$ de substrato. Posteriormente, as mudas foram transferidas para sacos de polietileno contendo $3 \mathrm{dm}^{3}$ do mesmo substrato, permanecendo em viveiro sob 30\% de sombreamento por um período de cinco meses, até se estabelecerem. Em seguida, as mudas foram submetidas a três níveis de sombreamento, 30\%, 50\% e $70 \%$, com o uso de sombrites, conforme a especificação do fabricante e um tratamento a pleno sol (0\%) como controle.

No final do período experimental, foram avaliadas características associadas a trocas gasosas (fotossíntese, condutância estomática e transpiração) em cinco repetições, consistindo cada planta uma repetição. As medições foram realizadas sempre em folhas simples completamente expandidas, localizadas no segundo nó contado a partir do ápice e, sempre que possível, em dias ensolarados e isentos de nuvens. As características de trocas gasosas citadas foram avaliadas com um analisador de gás infravermelho de fluxo aberto (LCA-4, Analytical Development Co., 
Hoddesdon, UK). Essas avaliações foram realizadas sempre no horário de 09:00 horas (hora solar). Foram coletadas também, de forma aleatória, cinco folhas simples em cada um dos tratamentos para a realização das análises de nitrogênio. O nitrogênio foliar foi analisado pelo método de micro-Kjeldahl.

A determinação dos teores de clorofila foi realizada em 5 plantas por tratamento, a partir de três folhas simples completamente expandidas retiradas na região mediana das plantas. As quantificações de clorofilas a, b e total foram realizadas segundo ARNON (1949).

O crescimento das plantas foi avaliado tomando por base as variáveis: comprimento; diâmetro do caule; área foliar; e massa seca: foliar, de caule e de raízes, em 15 plantas de cada tratamento.

A espessura do limbo foi avaliada por meio de seções transversais de lâminas semipermanentes de 10 folhas provenientes de dez plantas distintas, sendo as medições realizadas pelo microscópio KENA-VISION 2100 equipado com uma Ocular Micrométrica. As medidas foram realizadas em três campos por folha, perfazendo-se um total de 30 medições para cada tecido foliar por tratamento.

O delineamento experimental utilizado foi o inteiramente casualizado, com quatro tratamentos, sendo cada parcela experimental constituída de 25 plantas que foram aleatoriamente distribuídas em cada nível de radiação testado. Os dados foram submetidos à análise de variância seguido do teste de Tukey pelo programa estatístico SISVAR, versão 4.3 (FERREIRA, 1999).

\section{RESULTADOS E DISCUSSÃO}

Plantas sombreadas a $50 \%$ e a $70 \%$ tiveram taxas fotossintéticas reduzidas quando comparadas com os demais tratamentos estudados, ao passo que as plantas submetidas a $70 \%$ de sombreamento exibiram menor condutância estomática em relação às cultivadas em pleno sol (Tabela 1). Quanto à transpiração, não foram observadas diferenças entre os tratamentos, embora tenha sido verificado um aumento na condutância estomática e um incremento concomitante na fotossíntese líquida em níveis mais elevados de irradiância (Tabela 1). Em Croton urucurana Baill, uma espécie pioneira, ALVARENGA et al. (2003) verificaram também que as maiores taxas fotossintéticas ocorreram em plantas jovens cultivadas em níveis mais elevados de irradiância (30\% e a pleno sol).

Trabalhando com espécies tolerantes e sensíveis à sombra, RAMOS \& GRACE (1990) observaram resultados com tendências semelhantes em que os maiores valores de condutância estomática foram observados em plantas tolerantes cultivadas a pleno sol.

Em relação aos pigmentos clorofilianos, foram observados maiores valores de clorofila total e clorofila $a$ em folhas submetidas a $50 \%$ e $70 \%$ de sombreamento em relação aos demais níveis de irradiância. A concentração de clorofila $b$ foi menor em plantas cultivadas a pleno sol (Tabela 1), fato esse devido a processos fotoxidativos, favorecendo assim uma maior relação clorofila $a / b$ na citada condição de irradiância.

A redução no teor de clorofilas (por unidade de massa e, ou por unidade de área) em níveis mais elevados de irradiância é amplamente relatada na literatura, como registrado por ATROCH et al. (2001), KITAJIMA \& HOGAN (2003) e ALVARENGA et al. (2003), principalmente em espécies florestais.

Os níveis de clorofilas foliares são controlados pela luz, sendo que, em intensidades mais elevadas de radiação, as moléculas de clorofilas são mais passíveis a processos fotoxidativos, sendo o equilíbrio estabelecido com níveis de radiação mais baixas (KRAMER \& KOZLOWSKI, 1979). Portanto, folhas de sombra possuem, geralmente, maior concentração de clorofilas em relação às crescidas sob pleno sol (CASTRO, 2002; ALVARENGA et al., 2003).

Este tipo de resposta foi observado em plantas de Bauhinia forficata Link cujas condições de sombreamento (30\% e 50\%) favorecem, de forma inequívoca, o aumento das concentrações de clorofila total quando comparadas às plantas sob pleno sol (ATROCH et al., 2001).

A relação clorofila $a / b$ está relacionada diretamente com a capacidade das plantas em maximizar a captura de luz em condições de maior sombreamento (CRITCHLEY, 1999). O aumento da quantidade de clorofila $b$ em relação à clorofila $a$ estaria relacionada a uma maior proporção do fotossistema II, que é mais rico em clorofila " $b$ ” que “ $a$ ”, em relação ao fotossistema I (CRITCHLEY 1999; NAKAZONO et al., 2001), fato que favorece a capacidade adaptativa das plantas a ambientes com pouca radiação.

Folhas de plantas de $\boldsymbol{C}$. vernalis cultivadas sob $50 \%$ de sombreamento acumularam mais nitrogênio quando comparadas às cultivadas sob pleno sol e 30\% de sombreamento (Tabela 1).

Resultados semelhantes foram obtidos por EVANS \& POORTER (2001), estudando as relações entre ganho de carbono, concentração,

Ciência Rural, v. 35, n. 5, set-out, 2005. 
Tabela 1 - Fotossíntese líquida (A), condutância estomática (Gs), transpiração (T), teor de nitrogênio (TNF), teores de clorofilas a, b, total e relação clorofila a/b em folhas de plantas de Cupania vernalis Camb. submetidas a diferentes níveis de sombreamento.

\begin{tabular}{|c|c|c|c|c|}
\hline Tratamentos & $\begin{array}{c}\mathrm{A} \\
\left(\mu \mathrm{mol} \cdot \mathrm{CO}_{2} \cdot \mathrm{m}^{-2} \cdot \mathrm{s}^{-1}\right)\end{array}$ & $\begin{array}{c}\text { Gs } \\
\left(\mathrm{mol} \mathrm{H}_{2} \mathrm{O} \cdot \mathrm{m}^{-2} \cdot \mathrm{s}^{-1}\right)\end{array}$ & $\frac{\mathrm{T}}{\left(\mathrm{mmol} \mathrm{H}_{2} \mathrm{O} \cdot \mathrm{m}^{-2} \cdot \mathrm{s}^{-1}\right)}$ & TNF (\%) \\
\hline Pleno sol & 3,83 a & $0,046 \mathrm{a}$ & $1,51 \mathrm{a}$ & $1,0 \mathrm{~b}$ \\
\hline $30 \%$ de sombra & 3,82 a & $0,043 \mathrm{ab}$ & $1,48 \mathrm{a}$ & $1,2 \mathrm{~b}$ \\
\hline $50 \%$ de sombra & $2,81 \mathrm{~b}$ & $0,030 \mathrm{ab}$ & $1,55 \mathrm{a}$ & 3,0 a \\
\hline $70 \%$ de sombra & $2,62 \mathrm{~b}$ & $0,023 \mathrm{~b}$ & $1,04 \mathrm{a}$ & $2,0 \mathrm{ab}$ \\
\hline Tratamentos & $\begin{array}{l}\text { clor.a } \\
\mathrm{mg} \cdot \mathrm{g}^{-1} \mathrm{MF}\end{array}$ & $\begin{array}{l}\text { clor. } b \\
\mathrm{mg} \cdot \mathrm{g}^{-1} \mathrm{MF}\end{array}$ & $\begin{array}{l}\text { clor. total } \\
\mathrm{mg} \cdot \mathrm{g}^{-1} \mathrm{MF}\end{array}$ & relação clorofila $a / b$ \\
\hline Pleno sol & $0,900 \mathrm{~b}$ & $0,405 \mathrm{~b}$ & $1,305 \mathrm{~b}$ & $2,222 \mathrm{a}$ \\
\hline $30 \%$ de sombra & $0,995 \mathrm{~b}$ & $0,452 \mathrm{a}$ & $1,447 \mathrm{~b}$ & $2,201 \mathrm{a}$ \\
\hline $50 \%$ de sombra & $1,525 \mathrm{a}$ & 0,958 a & $2,483 \mathrm{a}$ & $1,591 \mathrm{~b}$ \\
\hline $70 \%$ de sombra & 1,659 a & 0,899 a & 2,558 a & $1,845 \mathrm{~b}$ \\
\hline
\end{tabular}

Médias não seguidas pela mesma letra diferem estatisticamente entre si, pelo teste de Tukey, a 5\% de probabilidade de erro.

particionamento de nitrogênio e área foliar específica em folhas de espécies de dicotiledôneas $C_{3}$. Esses autores verificaram que o maior teor de nitrogênio total foi verificado em folhas de plantas submetidas à baixa irradiância.

Na tabela 2, pode-se observar que ocorreu maior acúmulo de massa seca total em plantas cultivadas sob $50 \%$ de sombreamento em relação às de pleno sol. Observou-se, ainda, menor massa seca foliar nas plantas a pleno sol em relação às cultivadas sob $50 \%$ e $70 \%$ de sombreamento, enquanto plantas cultivadas sob $70 \%$ de sombreamento alocaram maiores quantidades de massa seca no caule em relação àquelas cultivadas a pleno sol. Na mesma tabela, verifica-se ainda que não houve diferença de massa seca do sistema radicular das plantas entre os tratamentos testados. O crescimento da parte aérea foi reduzido nas plantas cultivadas a pleno sol em relação àquelas sob $30 \%$ e $50 \%$ de sombreamento, fato que pode ser confirmado pelas relações raiz/parte aérea.

Em Vochysia tucanorum Mart., BARBOSA et al. (1999) verificaram maior massa seca total em plantas cultivadas sob $45 \%$ de radiação fotossinteticamente ativa quando comparadas com as cultivadas em níveis extremos de irradiância, como $100 \%$ e $4,8 \%$. Por outro lado, NAKAZONO et al. (2001), estudando o crescimento inicial de plantas de Euterpe edulis sob diferentes níveis de irradiância, observaram que as plantas apresentaram menor acúmulo de biomassa, menor taxa de crescimento e menor relação raiz/parte aérea quando cultivadas em $2 \%$ ou $6 \%$ de sombreamento quando comparadas com plantas cultivadas a pleno sol.

Maiores massas secas de folha, caule, raiz e total foram obtidas em plantas de Sclerolobium paniculatum cultivadas sob $50 \%$ de sombreamento e a relação raiz/parte aérea foi menor nas plantas cultivadas sob 90\% de sombreamento (FELFILI et al., 1999).

Estudando o efeito do sombreamento em plantas de Jacaranda copaia, CAMPOS \& UCHIDA (2002) observaram uma menor relação parte aérea/ raiz em plantas cultivadas em níveis mais elevados de sombreamento. Esses resultados são semelhantes aos obtidos nesse estudo com $\boldsymbol{C}$. vernalis, demonstrando que o sombreamento favorece o crescimento da parte aérea em detrimento do sistema radicular, considerando-se plantas cultivadas sob 30 e $50 \%$ de sombreamento. Entretanto, não foi verificada diferença neste parâmetro entre plantas cultivadas sob $70 \%$ de sombreamento e às cultivadas sob pleno sol.

Com relação à característica altura, plantas cultivadas a pleno sol tiveram menor porte. Entretanto, plantas cultivadas sob $70 \%$ de sombreamento tiveram maiores diâmetros de caule em relação aos demais tratamentos (Tabela 2).

Respostas semelhantes foram obtidas em várias espécies cuja característica de crescimento foi promovida pelo aumento de condições sombreadas (ATROCH et al., 2001; CAMPOS \& UCHIDA, 2002; ALVARENGA et al., 2003).

Maiores alturas e diâmetros de caule foram observados em plantas de Bauhinia forficata cultivadas sob 30\% de sombreamento (ATROCH et al, 2001).

Plantas cultivadas sob $50 \%$ e $70 \%$ de sombreamento formaram folhas com maior crescimento em superfície e mais delgadas em relação às cultivadas a pleno sol (Tabela 2), portanto com maior área foliar especifica (AFE).

No que diz respeito à área foliar total, vários estudos com inúmeras espécies arbóreas submetidas

Ciência Rural, v.35 n. 5, set-out, 2005. 
Tabela 2 - Massa seca de folhas, caules, raízes, total, relação raiz /parte aérea, crescimento em altura e em diâmetro do caule, área foliar, área foliar especifica (AFE) e espessura do limbo de folhas de plantas jovens de Cupania vernalis Camb. submetidas a diferentes níveis de sombreamento.

\begin{tabular}{|c|c|c|c|c|c|}
\hline \multirow{2}{*}{ Tratamentos } & \multicolumn{4}{|c|}{ Massa seca (g) } & \multirow{2}{*}{ Relação raíz/parte aérea } \\
\hline & Folhas & Caules & Raízes & Total & \\
\hline Pleno sol & $4,686 \mathrm{~b}$ & $2,022 \mathrm{~b}$ & $11,322 \mathrm{a}$ & $18,756 \mathrm{~b}$ & $1,518 \mathrm{a}$ \\
\hline $30 \%$ de sombra & $7,031 \mathrm{ab}$ & 3,356ab & $12,552 \mathrm{a}$ & $22,809 a b$ & $1,131 \quad b$ \\
\hline $50 \%$ de sombra & 9,159 a & $3,120 a b$ & 11,629 a & 25,407 a & $1,115 \mathrm{~b}$ \\
\hline $70 \%$ de sombra & 7,778 a & $3,624 \mathrm{a}$ & 11,838 a & $23,251 a b$ & $1,192 \mathrm{ab}$ \\
\hline Tratamentos & Altura (cm) & $\begin{array}{l}\text { Diâmetro do colo } \\
\text { (mm) }\end{array}$ & $\begin{array}{l}\text { Área foliar } \\
\text { Total }\left(\mathrm{dm}^{2}\right)\end{array}$ & $\operatorname{AFE}\left(\mathrm{dm}^{2} / \mathrm{g}\right)$ & Espessura do limbo $(\mu \mathrm{m})$ \\
\hline Pleno sol & $17,80 \mathrm{~b}$ & $7,70 \mathrm{c}$ & $4,33 \quad \mathrm{c}$ & $0,85 \mathrm{~b}$ & 169,53 a \\
\hline $30 \%$ de sombra & 22,65 a & $8,80 \mathrm{~b}$ & 6,57 bc & $0,88 \mathrm{~b}$ & $138,15 \mathrm{~b}$ \\
\hline $50 \%$ de sombra & 24,90 a & $9,00 \mathrm{~b}$ & $9,54 \mathrm{a}$ & $1,12 \mathrm{a}$ & 119,55 c \\
\hline $70 \%$ de sombra & $21,40 \mathrm{a}$ & 9,65 a & $8,55 a b$ & $1,11 \mathrm{a}$ & $119,10 \mathrm{c}$ \\
\hline
\end{tabular}

Médias não seguidas pela mesma letra, na coluna, diferem estatisticamente entre si, pelo Teste de Tukey, a 5\% de probabilidade de erro.

a diferentes níveis de irradiância sob condições de viveiro confirmam os resultados obtidos em $\boldsymbol{C}$. vernalis, destacando-se um aumento na superfície foliar com o aumento do sombreamento, a fim de compensar as menores taxas fotossintéticas sob condições mais sombreadas (SCALON et al., 2001; CAMPOS \& UCHIDA, 2002; MORAIS et al., 2003; ALVARENGA et al., 2003).

As maiores AFE foram observadas em plantas cultivadas sob $50 \%$ e $70 \%$ de sombreamento provavelmente devido a modificações na espessura das células epidérmicas e parênquimas (Tabela 2). O decréscimo na espessura foliar das plantas de $\boldsymbol{C}$. vernalis sob $70 \%$ de sombreamento provavelmente seja em decorrência da diferença na distribuição de fotoassimilados e crescimento em alongamento de caule, em relação às plantas cultivadas a pleno sol, que tiveram folhas mais espessas e menor altura do caule (Tabela 2). Essa característica mais espessa do limbo foliar poderá constituir-se em proteção para o aparelho fotossintético quanto a possíveis danos fotoxidativos promovidos por radiação excessiva. Alguns estudos têm demonstrado padrões de respostas anatômicas semelhantes, para os quais se observa um incremento na espessura do limbo com o aumento da irradiância (HANBA et al., 2002).

\section{CONCLUSÕES}

O sombreamento afeta, de forma inequívoca, as características de crescimento, trocas gasosas, teores de clorofilas foliares e conteúdo de nitrogênio em plantas de $\boldsymbol{C}$. vernalis, demonstrando a grande plasticidade desta espécie, quando submetida a diferentes níveis de sombreamento.

Melhor desempenho das plantas em termos de crescimento inicial ocorre em cultivos sob $50 \%$ e $70 \%$ de sombreamento, formando mudas de melhor padrão e qualidade.

\section{REFERÊNCIAS}

ALMEIDA, L.P. Germinação, crescimento inicial e anatomia foliar de plantas jovens de Cryptocarya aschersoniana Mez. sob diferentes níveis de radiação. 2001. 96f. Dissertação (Mestrado em Fisiologia Vegetal) - Curso de Agronomia/Fisiologia Vegetal, Universidade Federal de Lavras.

ALMEIDA, S.S. et al. Efeito de clareiras naturais na estrutura de plântulas de Vochysia guianensis Aubl. (Vochysiaceae), em floresta amazônica de terra firme. Boletim Museu Paraense Emilio Goeldi, Nova serie, Botânica, Belém, v.10, p.91103, 1994.

ALMEIDA, L.P., et al. Crescimento inicial de Cryptocarya aschersoniana Mez. submetidas a diferentes níveis de radiação solar. Ciência Rural, Santa Maria, v.34, n.1, p.83-88, 2004.

ALVARENGA, A.A., et al. Effects of differents ligth levels on the initial growth and photosynthesis of Croton urucurana Baill. In southeastern Brazil. Revista Árvore, Viçosa, v. 27, n. 1, p. 53-57, 2003.

ALVARENGA, A.A., et al. Desenvolvimento de mudas de Guarea [Guarea guidonea (L.) Sleumer]. Revista Daphine, Belo Horizonte, v.8, n.3, p.22-26, 1998.

ATROCH, E.M.A.C. et al. Crescimento, teor de clorofilas, distribuição de biomassa e características anatômicas de plantas jovens de Bauhinia forficata Link. Submetidas a diferentes condições de sombreamento. Ciência e Agrotecnologia, Lavras, v.25, n.4, p.853-862, 2001.

Ciência Rural, v. 35, n. 5, set-out, 2005. 
ARNON, D.I. Copper enzymes in isolates choroplasts. Polyphenoloxidade in Beta vulgaris. Plant Physiology, California, v.24, n.l, p.1-15, 1949.

BARBOSA, A.R. et al. Effect of light and temperature on germination and early growth of Vochysia tucanorum Mart. , Vochysiaceae, in cerrado and forest soil under different radiation levels. Revista Brasileira de Botânica, São Paulo, v.22, n.2, p.275-280, 1999

BRAND, M.H. Shade influences plant growth, leaf color and chlorophyll content of Kalmia latifolia L. cultivars. Hort Science, Alexandria, v.32, n.2, p.206-208, 1997.

CAMPOS, M.A.A.; UCHIDA, T. Influência do sombreamento no crescimento de mudas de três espécies amazônicas. Pesquisa Agropecuária Brasileira, Brasília, v.37, n.3, p.281-288, 2002.

CASTRO, E.M. Alterações anatômicas, fisiológicas e fotoquímicas em plantas de Mikania glomerata Sprengel (guaco) sob diferentes fotoperíodos e níveis de sombreamento. 2002. 221f. Tese (Doutorado em Fitotecnia) - Curso de Fitotecnia, Universidade Federal de Lavras.

CRITCHLEY, C. Molecular adaptation to irradiance: the dual functionality of photosystem II. In: SINGHAL, G.S. et al. (Ed) Concepts in photobiology: photosinthesis and photomorphogenesis. New Delhi: Narosa publishing House, 1999. p. 573-587.

DIAS FILHO, M.B. Physiological response of Solanum crinitum Lam. to contrasting light intensity. Pesquisa Agropecuária Brasileira, Brasília, v.32, n.8, p.789-796, 1997.

ELLSWORTH, D.S.; REICH, P. B. Leaf mass per area, nitrogen content and photosynthetic carbon gain in Acer saccharum seedlings in contrasting forest ligth environments. Functional Ecology, Oxford, v.6, n.4, p.423-435, 1992.

EVANS, J.R.; POORTER, H. Photosynthetic acclimation of plants to growth irradiance: the relative importance of specific area and nitrogen partitioning in maximizing carbon gain. Plant Cell and Environment, Oxford, v.24, n.8, p.755-767, 2001.

FELFILI, J.M., et al. Comportamento de plântulas de Sclerolobium paniculatum Vog. Var. rubiginosum (Tul.) Benth Sob diferentes níveis de sombreamento. Revista Brasileira de Botânica, São Paulo, v.22, n. 2, p.297-301, 1999.

FERREIRA, D.F. SISVAR 4. 3 - Sistema de análises estatísticas. Lavras: UFLA, 1999. 1 CD.

HANBA, Y.T.; KOGAMI, H.; TERASHIMA, L. The effects of growth irradiance on leaf anatomy and photosynthesis in Acer species differing in light demand. Plant Cell and Enviroment, Oxford, v.25, n.8, p.1021-1030, 2002.

KITAJIMA, K.; HOGAN, K.P. Increases of chlorophyll $a / b$ ratios during acclimation of tropical woody seedlings to nitrogen limitation and high light. Plant Cell and Environment, Oxford, v.26, n.6, p.857-865, 2003.

KRAMER, P.J.; KOSLOWSKI,T. Physiology of woods plants. New York: Academic, 1979. 811 p.

LORENZI, H. Árvores brasileiras: manual de identificação e cultivo de plantas arbóreas nativas do Brasil. 3.ed. Nova Odessa: Plantarum, 2000. v.1.

MORAIS, H. et al. Características fisiológicas e de crescimento de cafeeiro sombreado com guandu e cultivado a pleno sol. Pesquisa Agropecuária Brasileira, Brasília, v. 38, n. 10, p. 11311137, 2003.

NAKAZONO, E.M. et al. Crescimento inicial de Euterpe edulis Mart. em diferentes regimes de luz. Revista Brasileira de Botânica, São Paulo, v.24, n.2, p.173-179, 2001.

NASCIMENTO, M.T.; SADDI, N. Structure and composition in na área of cerrado in Cuiabá-MT, Brazil. Revista Brasileira de Botânica, São Paulo, v.15, n.1, p.47-55, 1992.

NAVES, V.L. et al. Comportamento estomático de mudas de três espécies florestais submetida a diferentes níveis de radiação fotossintéticamente ativa. Ciência e Prática, Lavras, v.18, n.4, p.408-414, 1994.

RAMOS, J.; GRACE, J. The effetcs of shade on the gás exchange of seedlings of four tropical trees from México. Functional Ecology, Oxford, v.4, n.5, p.667-677, 1990.

SCALON, S.P.Q. et al. Germinação e crescimento de mudas de pitangueira (Eugenia uniflora L.) sob condições de sombreamento. Revista Brasileira de Fruticultura, Jaboticabal, v.23, n.3, p.652-655, 2001.

VILELA, A.E.; RAVETTA, D.A. The effect of radiation on seedling growth and physiology in four species of Proposis L.(Mimosaceae). Journal of Arid Environmental, London, v.44, n.4, p.415-423, 2000.

WHATLEY, F.H.; WHATLEY, F.R. A luz e a vida das plantas: temas de biologia. São Paulo: EDUSP, 1982. V.30, 101p.

WHITMORE, T.C. A review of some aspects of tropical rain forest seedling ecology with suggestions for further enquiry. In: SWAINE, M.D. (Ed). The ecology of tropical forest tree seedlings - man and the biosphere series. New York, 1996. V.17, p.3-39. 